\title{
The Impact of Community Opening on Road Access
}

\author{
Fan Li ${ }^{1, a}$ \\ ${ }^{1}$ School of North China Electric Power University, Baoding 071003, China \\ a1662467637@qq.com
}

Abstract: This paper mainly studies the influence of community opening on road access, which is beneficial to perfect urban public service and optimize the structure of street network, so as to realize the maximum utilization of resources. When we study the influence of open area on the surrounding roads, we use the theory of traffic flow to study the TOPSIS model.

We select the appropriate evaluation index system(traffic flow, vehicle average speed and traffic density) to evaluate the impact of open area on the surrounding roads. Then, the relationship between vehicle average velocity and traffic volume and traffic density is obtained by referring to the relationship of traffic flow parameters. In order to study the influence of open area on the surrounding road traffic, this paper establishes the TOPSIS model. The three indexes (traffic flow, vehicle average speed and traffic density) are the index layer of the model. Using the analytic hierarchy process to determine the weight of each index, and finally build a weighted standard decision matrix. By the TOPSIS model, we get the positive and negative ideal schemes, and measure the merits and demerits of the schemes by calculating the relative proximity of the schemes and the positive and negative ideal schemes. When the relative proximity is closer to 1 , the closer the program is to the positive ideal solution, the better the scheme.

Taking the Yibin City Rhine River area of Sichuan Province as an example, combined with the real real-time travel speed data of the traffic website, by TOPSIS model we analyze the effect of the area before and after the opening on the surrounding road capacity, using MATLAB software to solve.

Key words: Traffic capacity, Analytic hierarchy process, TOPSIS model

\section{Introduction}

With the sustained and rapid growth of China's national economy, the level of urbanization has been significantly improved, but the continuous growth of urban population, but has brought the traffic congestion, environmental degradation and other negative effects[1].

City is an important carrier of economic and social development and people's production and life, is a symbol of modern civilization. Strengthen the planning and construction of the neighborhood, realize the internal road publicization, solve the problem which is the layout of the traffic network, rationally allocate the parking facilities, encourage the participation of the society, relax the market policy, and gradually ease the parking problem[2].

Therefore, it is necessary to provide a quantitative basis for scientific decision-making on the impact of community opening on the passage of the surrounding roads. 
2. Symbol Description

\begin{tabular}{c|c}
\hline $\mathrm{T}$ & Traffic flow, car / sec \\
\hline$V_{o v}$ & Travel speed, $\mathrm{km} / \mathrm{h}$ \\
\hline $\mathrm{K}$ & Traffic density, vehicle / km \\
\hline
\end{tabular}

\section{Model establishment and solution}

\subsection{TOPSIS Model [3] establishment and solution}

The basic idea of TOPSIS model is to get positive and negative ideal program, by calculating the relative proximity of the schemes to measure the merits of the program. Taking the Yibin City Rhine River area of Sichuan Province as an example, the establishment and solution of the model are as follows.

(1) solve the polar consistency matrix

Traffic flow(T), vehicle average speed $\left(V_{o v}\right)$ and traffic density $(\mathrm{K})$ are the index layer of the model[4]. Using the analytic hierarchy process to determine the weight of each index[5][6][7].Polarize the evaluation index. With MATLAB software, the polarized matrix is obtained as follows:

$$
X^{*}=\left[\begin{array}{ccc}
1199.94 & 32.17 & \frac{1}{37.3} \\
1199.95 & 58.25 & \frac{1}{20.6} \\
1049.18 & 25.10 & \frac{1}{41.8} \\
1026.02 & 35.28 & \frac{1}{29.1}
\end{array}\right]
$$

(2)analytic hierarchy process

The judgment matrix of the target layer and the criterion layer is constructed as follows.

$$
C=\left[\begin{array}{ll}
1 & 2 \\
\frac{1}{2} & 1
\end{array}\right]
$$

The judgment matrix of each criterion layer and index layer is as follows:

(1) the judgment matrix of the influence of the index layer on the surrounding road traffic.

$$
D=\left[\begin{array}{ccc}
1 & 4 & 2 \\
\frac{1}{4} & 1 & 3 \\
\frac{1}{2} & \frac{1}{3} & 1
\end{array}\right]
$$


Calculate the weight vector with MATLAB software, $\left(\begin{array}{lll}0.5782 & 0.2627 & 0.1591\end{array}\right)^{T}$, the largest eigenvalue $\lambda_{m}=3.3678, \mathrm{CI}=0.0092<0.1$.

(2) the judgment matrix of the influence of the index layer on the surrounding road service level

$$
E=\left[\begin{array}{lll}
1 & \frac{1}{4} & \frac{1}{3} \\
4 & 1 & \frac{1}{2} \\
3 & 2 & 1
\end{array}\right]
$$

The weight vector is $\left(\begin{array}{lll}0.1408 & 0.6778 & 0.1814\end{array}\right)^{T}$, the largest eigenvalue $\lambda_{m}$ $=2.6335, \mathrm{CI}=0.0091<0.1$.

Combination weight vector $\omega=\left(\begin{array}{lll}0.4324 & 0.4011 & 0.1665\end{array}\right)$.

Weighted normalized matrix is as follow.

$$
P=\left[\begin{array}{lll}
518.854 & 12.903 & 0.004 \\
518.858 & 23.364 & 0.008 \\
443.651 & 14.151 & 0.006
\end{array}\right]
$$

(3) Relative proximity

The distance from the scheme I to the ideal scheme is $L_{i}^{+}$. the distance to the negative ideal solution is $L_{i}^{-}$.

$$
\begin{aligned}
& L_{i}^{+}=\sqrt{\sum_{j=1}^{n}\left(r_{i j}-A_{j}^{+}\right)^{2}} \\
& L_{i}^{-}=\sqrt{\sum_{j=1}^{n}\left(r_{i j}-A_{j}^{-}\right)^{2}}
\end{aligned}
$$

Define the relative proximity:

$$
\lambda_{i}=\frac{L_{i}^{-}}{L_{i}^{+}+L_{i}^{-}}
$$

So $0<\lambda_{i}<1$.

When $\lambda_{\mathrm{i}}$ is close to 0 , the scheme $\mathrm{I}$ is closer to the negative ideal solution. So it is worse. When $\lambda_{\mathrm{i}}$ is close to 1 , the scheme $\mathrm{I}$ is closer to the ideal scheme. Then it is better. 
Therefore, the relative proximity of Yibin Rhine area before and after opening to the impact of the surrounding road traffic is shown in the following table.

Table3: relative proximity in Yibin City Rhine River district

\begin{tabular}{|c|c|c|}
\hline & before opening & after opening \\
\hline Champs Elysees & 0.6524 & 0.7440 \\
\hline $\begin{array}{c}\text { Middle of the } \\
\text { aerospace road }\end{array}$ & 0.2547 & 0.6668 \\
\hline
\end{tabular}

It can be seen from the table3, the two roads around the district after the opening, the relative proximity is greater than the district before the opening, more close to 1 , indicating that the program is closer to the ideal program. Among them, the middle of the aerospace road is more significant.

\section{Conclusion}

Through the study of open cell, we found that open areas help ease the traffic pressure to a certain extent. However, If fully open is too fast, not only will not reduce traffic congestion, but may cause urban planning chaos and frequent traffic accidents. In this regard, it is recommended that the relevant planning departments of the city first select a few typical district pilots. In addition, from the traffic management point of view: the gradual opening district should set some special traffic rules. For example: in the district road junctions set up delay signs to avoid road congestion and so on.

\section{References}

[1] Xia Chaoyang. Urban rail transit and land resources comprehensive development research [D]. Tongji University, 2006.

[2] The CPC Central Committee and State Council issued the "Opinions on Further Strengthening the Management of Urban Planning and Construction" [J]. The State Council of the People's Republic of China Gazette, 2016,07: 6-11.

[3] Wang Ying, Chen Kuangmin, Zhou Yan. Evaluation of Rail Transit Network Based on TOPSIS Model [J]. Journal of Highway and Transportation Research and Development, 2015,06: 130-134.

[4]Sichuan traffic public travel website service system: http://www.scjtcx.cn/road.jsp September 10, 2016

[5] Shanghai traffic travel network: http: //www.jtcx.sh.cn/zhishu/fastroad.jsp\#\#\# September 10, 2016

[6] Shenzhen City Transportation Committee (Shenzhen City Port Authority):

Http://szmap.sutpc.com/roadcongmore.aspx?page=1 September 10, 2016

[7] Sichuan traffic public travel website service system: http: //www.scjtcx.cn/road.jsp, September 10, 2016 